\title{
Produtividade sistêmica: conceitos e aplicações
}

\author{
Ney Cesar de Oliveira King ${ }^{a *}$, Edson Pinheiro de Lima ${ }^{b}$, Sérgio Eduardo Gouvêa da Costa \\ a*ney.king@pucpr.br, PUCPR, Brasil \\ be.pinheiro@pucpr.br, PUCPR, Brasil \\ 's.gouvea@pucpr.br, PUCPR, Brasil
}

\begin{abstract}
Resumo
0 estudo de temas relacionados à produtividade ocupa um lugar de destaque na agenda estratégica das empresas desde a gênese dos modelos de produção em massa. Vários modelos, processos e técnicas vêm sendo desenvolvidos com o propósito de melhorar os atuais níveis de desempenho das organizações. 0 conceito de produtividade evoluiu de uma abordagem unidimensional para um enfoque sistêmico, no entanto as diferentes técnicas desenvolvidas para a sua mensuração tratam de dimensões específicas. Há, portanto, a necessidade de se integrar tais técnicas em um modelo de gestão pela produtividade sistêmica, o que constitui o principal objetivo deste artigo. Partindo da construção de um conjunto de determinantes teóricos que representam a produtividade sistêmica, desenvolveu-se um processo para a sua mensuração utilizando-se como metodologia a abordagem por processos de Cambridge. Tal processo foi refinado via entrevistas e é ilustrado por um caso de simulação.
\end{abstract}

Palavras-chave

Produtividade sistêmica. Desempenho organizacional. Auditoria de negócios.

\section{Introdução}

A produtividade e os indicadores de produtividade vêm sendo utilizados ao longo do tempo por pessoas, organizações e nações para medir e acompanhar o próprio desempenho. Porém, em muitos casos, tais indicadores de produtividade são subutilizados, ou seja, por não serem trabalhados de forma sistêmica acabam por não fornecer uma visão integral das atividades. Com o intuito de explorar toda a potencialidade que a análise da produtividade pode fornecer, um modelo para a análise da produtividade sistêmica vem sendo desenvolvido ao longo dos últimos dez anos (DEMETER; CHIKÁN; MATYUSZ, 2011; INSTITUTO..., 2004; SUITO, 1998; CHENG; SILVA; LIMA, 1994).

0 conceito produtividade foi introduzido e desenvolvido nas organizações com o intuito de avaliar e melhorar o desempenho delas. Inicialmente, a produtividade era calculada pela razão entre 0 resultado da produção e o número de empregados. Por um longo período, esta fórmula representou a produtividade da organização. Com ela almejava-se o aumento da produção por empregado utilizado. Outras formas de medir a produtividade surgiram ao longo do tempo, relacionando o resultado da produção com a utilização de outros recursos como, por exemplo, energia, matéria-prima, insumos, entre outros (UKKO; TENHUNEN; RANTANEN, 2007; ORGANISATION..., 2005a; SINGH; MOTWANI; KUMAR, 2000).

Até hoje esses conceitos vêm sendo largamente utilizados como, por exemplo, na construção de índices comparativos entre países. Em parte, o uso dessas formas simplificadas de apuração de indicadores de produtividade se deve à complexidade que levantar dados apresenta e, adicionalmente, a diversidade de metodologias de cálculo adotadas por diferentes países dificulta a medição da produtividade por cálculos mais "qualificados". Portanto, para comparação mundial, a forma mais utilizada é a produtividade do trabalho, que é a razão entre o produto interno bruto - PIB - e o número de trabalhadores (ORGANISATION..., 2001).

0 Brasil tem conseguido pequenas melhorias nos indicadores de produtividade, quando comparado a países em desenvolvimento como China, Índia e Coréia, 
e até mesmo com países latino-americanos, como Colômbia e México. Em relação aos países da OECD (Organização para o Desenvolvimento Econômico e Cooperação), a razão é três vezes superior a favor desses países. As empresas brasileiras têm buscado rever as suas estratégias, visando desenvolver vantagens competitivas que sejam sustentáveis, sendo que a melhoria de seus indicadores de produtividade associada a uma visão ampliada e multifacetada podem contribuir para uma evolução nos níveis de desenvolvimento da indústria nacional (OLIVEIRA et al., 2011; ARBIX; DE NEGRI, 2005).

Há, portanto, a necessidade de se desenvolver um modelo integrado e sistêmico para a determinação da produtividade nas organizações, para que essas, atuando nos respectivos setores, construam vantagens comparativas. As medidas agregadas de produtividade se mostram pouco úteis à gestão das operações de uma empresa. Deve ser destacado, no entanto, que o crescente aumento da competitividade, somado às pressões trabalhistas, à crescente preocupação com a distribuição dos ganhos e à proteção do meio ambiente, demanda uma gestão da produtividade integrada e multidimensional. Deve-se, por conseguinte, trabalhar os aspectos relacionados à utilização de recursos e as várias dimensões envolvidas na apuração da produtividade em uma abordagem multivariada e sistêmica (OLIVEIRA; MARINS; ALMEIDA, 2010; BOOTHBY; DUFOUR; TANG., 2010; ORGANISATION..., 2005b; SINGH; MOTWANI; KUMAR, 2000; SUITO, 1998).

A visão de que os determinantes da produtividade das empresas referem-se a cada unidade organizacional, isoladamente, é ainda comum nos dias de hoje. Entretanto, nos últimos 30 anos essa concepção vem sofrendo fortes mudanças e em seu lugar têm sido difundidos novos sistemas e técnicas de gestão cujo princípio básico é o desenvolvimento de uma visão sistêmica da empresa. Têm-se como exemplos dessas novas abordagens integradas de gestão: o Just in Time - JIT; o Material Requirement Planning - MRP; Manufacturing Resources Planning - MRP 11, a gestão da qualidade total (Total Quality Management - TQM); a manutenção produtiva total (Total Productive Maintenance - TPM); e o Optimized Production Technology - OPT - baseado na teoria das restrições (Theory of Constrains - TOC) (DONE; VOSS; RYTTER, 2011; SOUSA; VOSS, 2008). 0 autor da TOC, Goldratt (1992), enfatiza a importância da visão sistêmica ou global da empresa ao afirmar que a otimização local da cada departamento ou de cada máquina não garante a otimização total da empresa.

A pesquisa relatada neste artigo busca responder a seguinte questão: como desenvolver um processo para a apuração da produtividade de uma organização levando em consideração os diferentes fatores que se interrelacionam para a sua determinação? Tal questão fundamenta o estabelecimento do seguinte objetivo geral: desenvolver um processo para determinar uma medida global da produtividade, adotando uma abordagem de natureza sistêmica e utilizando indicadores quantitativos e qualitativos para a construção de um indicador da produtividade sistêmica.

0 artigo está organizado da seguinte forma: apresenta-se incialmente o desenho metodológico da pesquisa para em seguida organizar-se a teoria na forma de um conjunto de determinantes teóricos que se sumarizam na escolha de uma abordagem para discutir a gestão pela produtividade sistêmica. Do referencial teórico propõe-se um processo para a implantação da gestão pela produtividade sistêmica e esse processo é sistematizado por uma técnica chamada abordagem de Cambridge. Desenvolvida a racionalidade de processo, ela é ilustrada com dados de uma caso de simulação. Destaca-se que a principal contribuição deste trabalho é sistematizar a ação de gestão pela produtividade sistêmica via abordagem de processos de Cambridge.

\section{Desenvolvimento da estratégia de pesquisa}

0 trabalho essencialmente tem como objetivo o desenvolvimento de um processo para instrumentalizar a apuração de um indicador global ou sistêmico de produtividade. Sendo assim, a abordagem metodológica escolhida fundamenta-se nos usos da pesquisa-ação e da abordagem por processos de Cambridge (process approach) (COUGHLAN; COGHLAN, 2002; PLATTS et al., 1996; THIOLLENT, 1994; PLATTS, 1993, 1994; PLATTS; GREGORY, 1990).

A estrutura lógica do trabalho prevê a construção de um referencial teórico na forma de processo, para, a partir dele, desenvolver a sua operacionalização. 0 processo instrumentalizado é refinado através de um conjunto de entrevistas com especialistas e ilustrado via simulação para apuração do indicador de produtividade global.

Platts (1993) ressalta que "é preciso reconhecer claramente que esse tipo de pesquisa que adota a abordagem por processo não objetiva o desenvolvimento de uma teoria descritiva, mas o desenvolvimento de processos que irão operacionalizar frameworks existentes e prover as empresas de manufatura com abordagens práticas para a melhoria de suas operações".

No que se refere à instrumentalização de conceitos, a abordagem de processos de Cambridge (process approach) cria uma sequência de fases, sendo cada fase composta por passos. A coleta de dados se 
dá num processo dinâmico de pesquisa-ação que emprega folhas de tarefa usadas para sistematizar a recuperação de informações, além de outras ferramentas como planilhas eletrônicas e mapas cognitivos. 0 preenchimento de cada folha de tarefa é individual, sendo realizado um "preenchimento final" de cada uma delas, como o resultado dos workshops (PLATTS et al., 1998; PLATTS; GREGORY, 1990).

A técnica a ser utilizada como forma de estabelecer um processo passo a passo, na aplicação do sistema de gestão através da produtividade sistêmica, foi a abordagem por processos que, conforme Platts (1994), é uma abordagem de pesquisa aplicada para o desenvolvimento, teste e refinamento de processos de operacionalização de frameworks conceituais. Constitui-se de uma metodologia prática voltada à melhoria da atuação gerencial nas organizações, caracterizada pela aplicação de estratégias conhecidas como quatro Ps: ponto de entrada, procedimento, gestão do projeto e participação.

No Quadro 1 é apresentada de forma geral a adaptação da abordagem por processo ao sistema de gestão através da produtividade sistêmica, na qual para cada um dos pontos estão definidos os procedimentos a serem executados, cujos detalhamentos e características de praticidade que toda metodologia deve proporcionar serão apresentados a seguir.

0 destaque de algumas características referentes à abordagem metodológica da pesquisa-ação, bem como de algumas propriedades da metodologia da abordagem de processos de Cambridge são importantes para qualificar o estudo desenvolvido.

A pesquisa-ação, segundo Thiollent (1994), é uma estratégia metodológica de pesquisa social: na qual há uma ampla e explícita interação entre pesquisadores e pessoas implicadas na situação investigada; da qual resulta a ordem de prioridade dos problemas a serem pesquisados e das soluções a serem encaminhadas, sob forma de ações concretas; cujo objetivo consiste em resolver ou, pelo menos, esclarecer os problemas da situação estudada; em que há, durante o processo, um acompanhamento das decisões, das ações e de toda a atividade intencional dos atores da situação.

Dadas as características que definem a estratégia de pesquisa, pode-se trabalhar o referencial teórico e na sequência desenvolver o processo para a determinação de uma medida para a produtividade sistêmica.

\section{Desenvolvendo um conceito para produtividade}

Até assumir o presente conceito econômico da razão entre entradas e saídas, a produtividade veio sendo definida de diferentes maneiras por diferentes pessoas no decorrer dos séculos. Entradas correspondem aos recursos empregados no processo produtivo como matéria-prima, equipamentos, trabalho e outros fatores de produção, enquanto que saídas correspondem aos resultados do processo produtivo, obtidos por intermédio da utilização desses recursos. Em outras palavras, produtividade corresponde a uma medida para se verificar quão bem os recursos para se produzir um determinado resultado são empregados (SHIMIZU; WAINAI; AVEDILLO-CRUZ, 1997).

A sustentabilidade das organizações produtivas passa necessariamente pelo processo de melhoria contínua dos seus processos de gestão. 0 setor produtivo deve compatibilizar a busca pelo desenvolvimento econômico com a preservação das condições de vida, a integração dos sistemas de gestão da qualidade, da gestão ambiental e da segurança e saúde ocupacional e pelo exercício da responsabilidade social e é justamente dentro dessa visão que se desenvolvem os modelos de produtividade sistêmica (OLIVEIRA, 2002).

0 Quadro 2 sumariza como a produtividade é definida por diferentes centros internacionais de

Quadro 1. Abordagem por processo para a produtividade sistêmica.

\begin{tabular}{llll}
\hline \multicolumn{1}{c}{ Procedimento } & \multicolumn{1}{c}{ Etapas do diagnóstico } \\
\hline & \multicolumn{1}{c}{ Participação } & \multicolumn{1}{c}{ Gestão do projeto } & Ponto de entrada \\
\hline - Coleta e análise das informações. & $\begin{array}{l}\text { administração e de todas as } \\
\text { - ldentificação das oportunidades }\end{array}$ & partes interessadas através do & \\
de melhoria através da & entendimento e compreensão da & - ldentificar os responsáveis pela & - Buscar o entendimento e \\
identificação dos pontos fortes e & produtividade sistêmica. & execução do plano de ação. & concordância dos grupos de \\
pontos passíveis de melhoria. & - Entrevistas e reuniões utilizando & - Estabelecer os grupos de apoio & gerencia e operação. \\
- Utilização de ferramentas & seminários abertos à discussão & e de operação. & - Objetivos e metas devem estar \\
e técnicas de fácil uso e & para a obtenção de uma posição & - Definição de um cronograma & declarados e ser de conhecimento \\
compreensão. & positiva das partes interessadas. & para o plano de ação. & das partes interessadas. \\
- Registro dos resultados obtidos & - Estabelecer em conjunto & & \\
em cada fase do processo. & um plano de ação de forma & & \\
& participativa. & & \\
\hline
\end{tabular}


produtividade. Essas definições fundamentaram a criação do modelo de gestão pela produtividade sistêmica.

Segundo Suito (1998), a gestão integrada da produtividade deve ter dois propósitos principais: integrar e sistematizar todas as técnicas e sistemas cujo objetivo é a melhoria contínua da produtividade da empresa; construir um sistema que seja o suficientemente flexível e ágil para adaptar-se às frequentes inovações (processos e produtos) desenvolvidas na organização.

Singh, Motwani e Kumar (2000) destacam que para uma empresa permanecer competitiva é necessário uma gestão integrada e eficiente. A gestão do desempenho deve refletir a estratégia de operações adotada e implementada. Novamente verifica-se a necessidade de uma gestão integrada do desempenho, ou seja, a produtividade tem de ser gerenciada através de uma abordagem sistêmica e vinculada à estratégia de operações.

A gestão da produtividade é realizada de diferentes maneiras e em diferentes níveis nas empresas. 0 Quadro 3 apresenta uma compilação de diferentes usos do conceito produtividade em áreas do conhecimento como Gestão de Operações, da Qualidade, de Serviços, da Manufatura e da Tecnologia, Engenharia Industrial, Economia Industrial, Desenvolvimento Social e Tecnologia da Informação e Comunicação, em que se observam os níveis de aplicação e diferentes dimensões de desempenho interrelacionadas.
0 trabalho desenvolvido é fundamentado na definição do Centro de Produtividade do Japão:

Produtividade é minimizar cientificamente o uso de recursos materiais, mão de obra, equipamentos etc., para reduzir custos de produção, expandir mercados, aumentar o número de pessoas empregadas, lutar por aumentos reais de salários e pela melhoria do padrão de vida no interesse comum do capital, trabalho e consumidores 2010, 1030.

Tal declaração está em sintonia com os conceitos desenvolvidos por Suito (1998) e Singh, Motwani e Kumar (2000) em que se desenvolve uma perspectiva de gestão integrada da produtividade apoiada na melhoria contínua e na inovação de produtos e processos.

Apresentados os conceitos que definem a produtividade e articuladas as suas características de gestão, pode-se, então, desenvolver um processo para a sua medição.

\section{Desenvolvendo um processo para a gestão da produtividade}

Se o objetivo é aumentar a produtividade, é necessário medi-la. Tradicionalmente, os indicadores econômico-financeiros são "eficientes", mas se a empresa quer obter resultados "efetivos" é necessário que esses indicadores estejam devidamente interligados aos indicadores de produtividade, uma vez que o

Quadro 2. A visão dos centros internacionais de produtividade.

\begin{tabular}{|c|c|}
\hline Centros internacionais de produtividade & Definições \\
\hline Organização Européia para Cooperação Econômica & $\begin{array}{l}\text { Produtividade é um quociente obtido na divisão de um produto por um de seus } \\
\text { elementos de produção. }\end{array}$ \\
\hline Associação Européia de Produtividade & Produtividade é o grau de utilização efetiva dos meios de produção. \\
\hline Centro de Produtividade do Japão & $\begin{array}{l}\text { Produtividade é minimizar cientificamente o uso de recursos materiais, mão de obra, } \\
\text { equipamentos etc. para reduzir custos de produção, expandir mercados, aumentar o } \\
\text { número de empregados, lutar por aumentos reais de salários e pela melhoria do padrão } \\
\text { de vida no interesse comum do capital, trabalho e consumidores. }\end{array}$ \\
\hline Centro Nacional de Produtividade de Cingapura & $\begin{array}{l}\text { Produtividade é uma atitude da mente que busca atingir melhorias contínuas nos } \\
\text { sistemas e nas práticas que traduzem as atitudes em ações. }\end{array}$ \\
\hline Conselho de Produtividade de Hong Kong & $\begin{array}{l}\text { Produtividade é a relação entre saída e entrada. Deve ser vista como a adição de valor } \\
\text { pela otimização. É um conceito total que direciona os elementos-chave da competição, } \\
\text { como inovação, custo, qualidade e entrega. }\end{array}$ \\
\hline Prêmio Nacional da Qualidade Malcolm Baldridge & $\begin{array}{l}\text { Produtividade refere-se a medidas de eficiência no uso dos recursos. Embora o termo } \\
\text { seja aplicado para fatores únicos como mão de obra (produtividade do trabalho), } \\
\text { máquinas, materiais, energia e capital, o conceito produtividade aplica-se também ao } \\
\text { total de recursos consumidos na produção de bens. A combinação normalmente requer } \\
\text { que se tenha uma média ponderada de diferentes medidas dos fatores únicos, onde o } \\
\text { peso tipicamente reflete o custo dos recursos. } 0 \text { uso de uma medida agregada como a } \\
\text { produtividade total dos fatores permite determinar se os efeitos das mudanças globais } \\
\text { em um processo - possivelmente envolvendo equilíbrio de recursos - são benéficos ou } \\
\text { não. }\end{array}$ \\
\hline Instituto Nacional da Produtividade da África do Sul & $\begin{array}{l}\text { Acima de tudo, produtividade é uma atitude da mente. É a determinação para melhorar } \\
\text { o desempenho de ontem e fazer ainda melhor amanhã. É a vontade de melhorar a } \\
\text { situação presente, independentemente de quão boa ela possa parecer. É o esforço } \\
\text { sustentado para aplicar novas técnicas e métodos. É a fé no progresso. }\end{array}$ \\
\hline
\end{tabular}


Quadro 3. Aplicando o conceito de produtividade.

\begin{tabular}{llll}
\hline Autor & Definição de produtividade & \multicolumn{1}{c}{ Abordagem utilizada } & Implicações para o trabalho \\
\hline & A produtividade é uma medida & Análise dos fatores & \\
global e unidimensional, no nível & determinantes no aumento da & 0 efeito da integração da produção \\
Joel e Daniel (2010) & $\begin{array}{l}\text { das economias de escala, que } \\
\text { integra operações de manufatura } \\
\text { e serviços. }\end{array}$ & $\begin{array}{l}\text { de bens e na prestação de } \\
\text { serviços. }\end{array}$ & de bens e da prestação de serviços.
\end{tabular}

Desenvolvem um conceito de produtividade baseado em múltiplos fatores em que trabalhadores mais qualificados proporcionam melhor

Boothby, Dufour e Tang (2010) desempenho que trabalhadores menos qualificados, equipamentos e tecnologias mais avançadas proporcionam melhores resultados que equipamentos e tecnologias mais maduras e assim por diante.

Desenvolve no nível da indústria o conceito de produtividade multifatorial.

Integração entre medidas de desempenho, produtividade e a gestão de instalações e projeto de fábrica.

A produtividade está associada a medidas de desempenho de processos-meio, observadas à luz da mobilização e conversão de recursos em trabalho e serviços.

A evolução dos indicadores de

Nanere et al. (2007)

Karmakar e Apte (2007)

Holweg (2007)

Sahay (2005)

Sadikoglu (2005)

Lentz e Mortensen (2005)

Gronroos e Ojasal (2004)

Spithoven (2003)

Define a produtividade como produtividade define a qualidade do desenvolvimento sustentável.

0 crescimento da produtividade está associado com a importância dada à gestão da informação.

A produtividade é resultado da melhoria nas operações de um sistema de produção enxuto.

Define a produtividade através de um indicador multifatorial para organizações de serviço.

Define a produtividade no âmbito da organização do trabalho e da sua integração com o processo produtivo.

Relaciona produtividade com a geração de valor agregado.

uma medida de como os recursos Desenvolve uma visão de como de entrada são utilizados e transformados em valor para os clientes.

A produtividade determina a melhoria no padrão ou qualidade de vida de uma sociedade. gerais da empresa, mais do que
Análise do crescimento da produtividade multifatorial (MFP) de natureza econômica.

Base de dados para comparação das informações da indústria de países desenvolvidos no que se refere à produtividade multifatorial.

Aplicações de técnicas de benchmarking para avaliar o desempenho de plantas produtivas.

Vincula a produtividade a um sistema integrado de medição de desempenho nos níveis organizacionais e individual.

Faz uma análise de como os indicadores de produtividade podem ser usados para avaliar o desenvolvimento sustentável. Ressalta a importância da informação no desenvolvimento das organizações.

Sistema Toyota de Produção como benchmarking para as organizações.

Nas operações de serviço, procura focar a atenção dos empregados nos objetivos nos objetivos específicos das unidades organizacionais.

Gestão da qualidade total - TQM - abordagem japonesa modificada.

Produtividade como sendo heterogênea e busca o equilíbrio em uma análise homogênea. diferentes fatores influenciam a melhoria da produtividade.

Faz um levantamento dos problemas causados pela falta de produtividade e as suas implicações na sociedade, particularmente para os atores envolvidos. ncorpora perspectivas econômicas a um conjunto heterogêneo de fatores determinantes da produtividade.

Nível agregado de definição da produtividade (indústria) baseada em múltiplos fatores.

Desenvolve um conceito global e sistêmico para avaliar o desempenho de uma planta produtiva.

Integração dos sistemas de gestão organizacionais com os níveis individuais do trabalho.

Relacionar questões ambientais com indicadores da produtividade, incluindo na apuração da

produtividade fatores ambientais.

Desenvolve um modelo referencial para gestão da informação para a produtividade.

Demonstra a importância da análise de indicadores relacionados aos meios de produção.

Demonstra a importância de se medir a produtividade sistêmica utilizando cinco fatores e dois referenciais.

Trabalha a integração do trabalho no chão de fábrica com o desempenho global do sistema produtivo.

Demonstra que a produtividade deve ser analisada sob vários fatores.

Propõe uma visão mais abrangente, fundamentada em diferentes fatores que influenciam a medição sistêmica da produtividade.

Enfatiza a importância do referencial de distribuição dos resultados, possibilitando a continuidade do movimento pela produtividade 
Quadro 3. Continuação...

\begin{tabular}{|c|c|c|c|}
\hline Autor & Definição de produtividade & Abordagem utilizada & Implicações para o trabalho \\
\hline Nin et al. (2003) & $\begin{array}{l}\text { Indicadores parciais e totais } \\
\text { direcionados a um único } \\
\text { objetivo. }\end{array}$ & $\begin{array}{l}\text { Estudo da produtividade } \\
\text { no setor agrícola de } \\
115 \text { países desenvolvidos e em } \\
\text { desenvolvimento. }\end{array}$ & $\begin{array}{l}\text { Caracteriza a importância dos } \\
\text { indicadores parciais e totais } \\
\text { de produtividade para analisar } \\
\text { crescimento e desenvolvimento. }\end{array}$ \\
\hline Huang et al. (2003) & $\begin{array}{l}\text { A produtividade é tratada como } \\
\text { um indicador de eficiência. }\end{array}$ & $\begin{array}{l}\text { Utilização de um software de } \\
\text { simulação para quantificar e } \\
\text { definir os pontos passíveis de } \\
\text { melhoria. }\end{array}$ & $\begin{array}{l}\text { Possibilita a utilização de simulação } \\
\text { para realizar benchmarking. }\end{array}$ \\
\hline Kumbhakar (2002) & $\begin{array}{l}0 \text { crescimento da produtividade } \\
\text { está causalmente ligado com a } \\
\text { geração de "lucro". }\end{array}$ & $\begin{array}{l}\text { Estudo da produtividade total } \\
\text { dos fatores usando como } \\
\text { parâmetro o "lucro". }\end{array}$ & $\begin{array}{l}\text { Realiza uma análise empírica sobre } \\
\text { questões relativas ao aumento } \\
\text { da produtividade e produção de } \\
\text { resultados econômicos. }\end{array}$ \\
\hline Hameri e Lehtonen (2001) & $\begin{array}{l}\text { Relaciona a melhoria da } \\
\text { produtividade com a utilização } \\
\text { da capacidade total dos } \\
\text { equipamentos com o mínimo de } \\
\text { desperdício. }\end{array}$ & $\begin{array}{l}\text { Comparação entre quatro } \\
\text { indicadores; baseado } \\
\text { no volume, demanda, } \\
\text { investimento de capital e } \\
\text { turnover. }\end{array}$ & $\begin{array}{l}\text { Destaca a importância de se trabalhar } \\
\text { a melhoria dos indicadores de } \\
\text { desempenho dos meios de produção } \\
\text { e a preocupação com os estoques. }\end{array}$ \\
\hline Chung (2001) & $\begin{array}{l}\text { É o resultado da melhor } \\
\text { aplicação de TQM. }\end{array}$ & $\begin{array}{l}\text { Comparação através das } \\
\text { atividades de TQM em } \\
\text { uma amostragem de } 160 \\
\text { organizações distribuídas } \\
\text { entre manufatura, serviços } \\
\text { relacionados à manufatura e } \\
\text { serviços. }\end{array}$ & $\begin{array}{l}\text { Demonstra que a melhoria na } \\
\text { utilização dos meios de produção } \\
\text { (TQM) e a aplicação do referencial } \\
\text { de comparação (benchmarking) são } \\
\text { importantes para a melhoria da } \\
\text { produtividade. }\end{array}$ \\
\hline Chen e Liaw (2001) & $\begin{array}{l}\text { Define como a eficiência de uma } \\
\text { organização em converter as } \\
\text { entradas do processo em produto } \\
\text { final. }\end{array}$ & $\begin{array}{l}\text { Pesquisa } 14 \text { itens relacionados } \\
\text { à gestão da produção através } \\
\text { de questionário aplicado em } \\
50 \text { organizações de quatro } \\
\text { setores industriais. }\end{array}$ & $\begin{array}{l}\text { Demonstra a importância dos fatores } \\
\text { relacionados aos meios de produção } \\
\text { na gestão da produtividade sistêmica. }\end{array}$ \\
\hline Chen, Liaw e Chen (2001) & $\begin{array}{l}\text { Define produtividade como } \\
\text { um indicador para medir o } \\
\text { desempenho econômico/ } \\
\text { financeiro. }\end{array}$ & $\begin{array}{l}\text { Construção de modelos } \\
\text { estatísticos dentro de padrões } \\
\text { financeiros. }\end{array}$ & $\begin{array}{l}\text { Vem demonstrar que a melhoria no } \\
\text { desempenho econômico e financeiro } \\
\text { está diretamente relacionada com o } \\
\text { crescimento da produtividade. }\end{array}$ \\
\hline Sengupta (1999) & $\begin{array}{l}\text { Indicadores devem ser } \\
\text { concebidos dentro de uma } \\
\text { visão sistêmica e observando } \\
\text { a dinâmica dos sistemas de } \\
\text { produção. }\end{array}$ & $\begin{array}{l}\text { Desenvolve uma abordagem } \\
\text { dinâmica para a produtividade, } \\
\text { propondo ajustes nas } \\
\text { estruturas de custo. }\end{array}$ & $\begin{array}{l}\text { Fortalece o desenvolvimento de uma } \\
\text { abordagem sistêmica para a gestão } \\
\text { da produtividade. }\end{array}$ \\
\hline
\end{tabular}

Fonte: Os autores (2011).

"lucro" está intimamente relacionado aos esforços de melhoria da produtividade (KUMBHAKAR, 2002; CHEN; LIAW; CHEN, 2001).

Sahay (2005) desenvolve um processo para a apuração de uma medida para a produtividade em serviços baseado em múltiplos fatores, na integração estratégica e na aplicação em diferentes níveis organizacionais. Tais características permitem que se desenvolva uma visão sistêmica acerca da produtividade, conforme pode ser observado na Figura 1.

Procura-se, com a gestão pela produtividade sistêmica, o desenvolvimento de um processo de melhoria contínua. Nesse sentido, o uso de um PDCA pode ajudar a melhor entender a necessidade, as fases e aplicabilidade do modelo de gestão. 0 Quadro 4 apresenta as etapas de implantação de um processo de gestão pela produtividade.

As etapas e atividades descritas no Quadro 4 podem ser detalhadas conforme apresentado no Quadro 5.
Apresentado o processo de implantação e gestão pela produtividade sistêmica, pode-se trabalhar os detalhes do seu processo de implantação através da sua operacionalização. A abordagem por processos de Cambridge sistematiza a aplicação e garante o desenvolvimento de um processo colaborativo e integrador. 0 ponto central desta pesquisa passa a ser uma discussão sobre a implementação do processo descrito no Quadro 5.

\section{A gestão da implantação da produtividade sistêmica}

Esta fase do trabalho procura estabelecer uma integração entre o modelo de processo da produtividade sistêmica e a sua "operacionalização" via abordagem por processos de Cambridge. A linha de desenvolvimento do trabalho passou da construção de um conceito para a gestão pela produtividade sistêmica, que foi modelada em um processo (Quadro 5) que será discutido nesta seção no que se refere à organização de seu uso. 


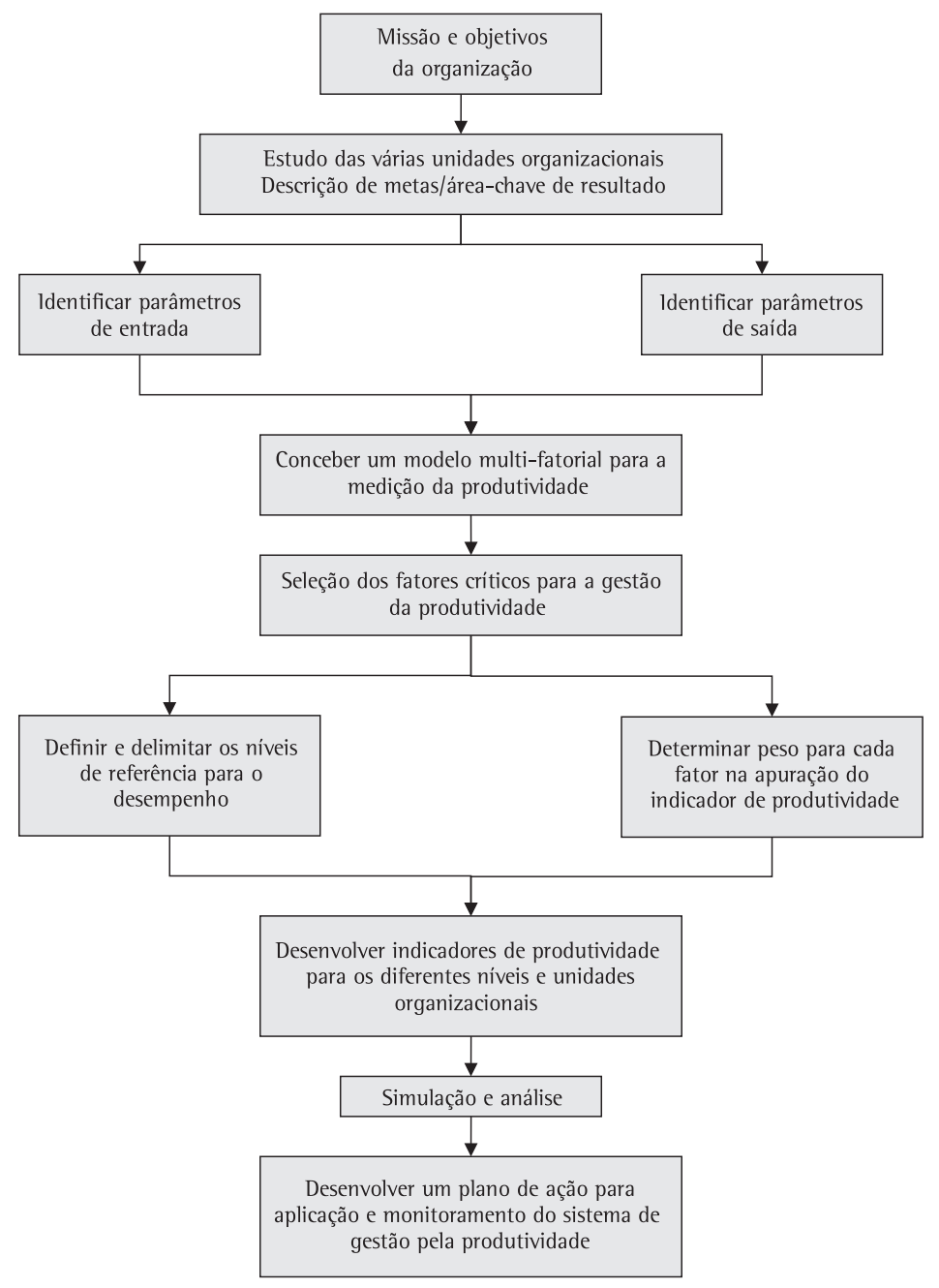

Figura 1. Processo adotado para medição da produtividade multifatorial. Fonte: Sahay (2005).

A abordagem de processos de Cambridge contribui para a construção coletiva de conhecimento acerca da implantação da gestão pela produtividade sistêmica.

0 Quadro 6 organiza as etapas e atividades que compõem o modelo de implantação da gestão pela produtividade sistêmica no sistema de aspectos que define a abordagem por processos de Cambridge. São apresentados os seus quatro elementos constitutivos conforme estabelecido por Platts (1994). Observa-se que os quatro Ps, ponto de entrada, procedimento, participação e gestão de projetos, são descritos e associados aos elementos que instrumentalizam o processo de gestão pela produtividade sistêmica.

Alguns dos procedimentos operacionais adotados merecem uma melhor consideração, particularmente a priorização de fatores de produtividade e das contramedidas que constam dos itens 2.4 e 3.1. Utilizou-se a técnica AHP (Analytical Hierarchy Process) para priorizarão dos fatores e das contramedidas (SARKIS, 2003).

A técnica AHP consiste em elaborar uma matriz com os fatores de produtividade sistêmica e comparar o fator que está alocado nas linhas com os fatores alocados nas colunas (Tabela 1), pontuando cada uma das relações com os valores constantes do Quadro 7.

0 valor 9 representa o maior grau de importância (quando o fator em comparação for mais importante/superior que o outro fator), o valor 1 representa o mesmo grau de importância (quando o fator em comparação tiver a mesma importância que o outro fator) e o valor $1 / 9$ representa o menor grau de importância (quando o fator em comparação for menos importante/inferior que o outro fator).

A Tabela 1 apresenta um exemplo de priorização em que são trabalhados os seguintes fatores de produtividade: fator gestão $-\mathrm{F}_{\mathrm{G}}$, fator humano $-\mathrm{F}_{\mathrm{H}}$, 
Quadro 4. 0 ciclo PDCA da gestão pela produtividade.

\begin{tabular}{|c|c|c|c|}
\hline PDCA & & Etapas & Objetivo \\
\hline \multirow{3}{*}{$\mathrm{P}$} & 1 & Diagnóstico & Levantar os dados globais (quantitativos e qualitativos) da organização. \\
\hline & 2 & Análise & $\begin{array}{l}\text { Investigar e/ou verificar quantitativa e qualitativamente os fatores que apresentam problemas e suas } \\
\text { causas principais. }\end{array}$ \\
\hline & 3 & Plano de ação & $\begin{array}{l}\text { Estruturar um plano de ação que proporcione melhorias de forma sistêmica, considerando o conceito } \\
\text { desenvolvimento sustentável. }\end{array}$ \\
\hline $\mathrm{D}$ & 4 & Execução & Implementar as mudanças e/ou melhorias definidas. \\
\hline \multirow{3}{*}{$\mathrm{C}$} & 5 & Verificação & $\begin{array}{l}\text { Acompanhar de forma sistemática a mudança, nas fases de implantação ou conclusão } \\
\text { (monitoramento). }\end{array}$ \\
\hline & 6 & Comparação & Mensurar os resultados obtidos através de uma nova medição. \\
\hline & 7 & $\begin{array}{l}\text { Os objetivos foram } \\
\text { alcançados? }\end{array}$ & Desenvolver uma avaliação de resultados. \\
\hline \multirow[b]{2}{*}{ A } & 8 & Padronização & Tem o objetivo de evitar ou prevenir a repetição dos problemas identificados. \\
\hline & 9 & Conclusão & $\begin{array}{l}\text { Recapitular o processo a fim de: } \\
\text { - ldentificar novos problemas ou oportunidades de melhoria; } \\
\text { - Ensinar a empresa a adotar um processo de melhoria contínua sistêmico. }\end{array}$ \\
\hline
\end{tabular}

Fonte: IBQP (INSTITUTO..., 2004).

Quadro 5. Descrição das atividades da implantação da gestão pela produtividade.

\begin{tabular}{ll}
\hline \multicolumn{1}{c}{ Etapas } & \multicolumn{1}{c}{ Atividades } \\
\hline \multirow{3}{*}{ 1. Diagnóstico } & 1.1 Contatos iniciais \\
& 1.2 Coletar dados e informações (se os dados apresentarem inconsistência, solicitar complementos ou verificações) \\
& 1.3 Aplicar a análise quantitativa da Produtividade Sistêmica (indicadores e desdobramento dos indicadores de produtividade) \\
& 1.4 Com base no resultado da análise quantitativa aplicar o diagnóstico qualitativo \\
& 2.1 Aplicar o cruzamento dos dados (análise quantitativa versus análise qualitativa) \\
& 2.2 ldentificar pontos fortes e passíveis de melhoria \\
2. Análise & 2.3 Fazer um detalhamento dos problemas \\
& 2.4 Priorizar as soluções \\
3. Plano de Ação & 3.1 Estabelecer a estratégia de ação \\
& 3.2 Estabelecer metas, prazos e responsabilidades \\
4. Execução & 4.1 Implementar as mudanças e melhorias definidas. \\
5. Verificação & 5.1 Monitorar as mudanças em andamento ou já concluídas (verificar se as mudanças foram efetivas e suficientes) \\
& 6.1 Aplicar nova medição dos indicadores da Produtividade Sistêmica \\
6. Comparação & 6.2 Comparar o planejado com o realizado \\
& 6.3 Analisar os resultados obtidos \\
& 6.4 Verificar se houve melhoria de forma sistêmica \\
7. Padronização & 7.1 Padronizar as melhorias implementadas a fim de evitar a sua reincidência \\
8. Conclusão & 8.1 ldentificar novos problemas ou oportunidades de melhorias \\
& 8.2 Aplicar um novo PDCA (recomeçar o processo) \\
\hline
\end{tabular}

Fonte: Os autores (2011).

fator meios de produção $-F_{M P}$, fator inventários $-F_{1}$ e fator recursos naturais $-\mathrm{F}_{\mathrm{RN}}$.

Uma vez definido quais são os fatores de produtividade que merecem maior atenção, devem ser levantadas quais são as contramedidas cabíveis que possam melhorar os pontos fracos e fortalecer os pontos fortes. Cabe nesse momento lembrar que qualquer contramedida que se levante afeta todos os fatores. Nessa etapa é interessante que as contramedidas não ultrapassem o número de 10 (INSTITUTO..., 2004).

Após discutidas e levantadas com a equipe do projeto as contramedidas cabíveis para a organização, é necessário também priorizar as contramedidas.
Nesse caso recomenda-se a utilização da matriz de priorização, em que os itens são avaliados conforme a sua importância/abrangência, emergência e viabilidade (ver Tabela 2).

Quanto à pontuação, para cada item a equipe pode discutir e atribuir valor único de consenso. Soma-se então o valor obtido em cada uma das colunas - as ações com maior pontuação serão as mais prioritárias. Isto não quer dizer que se deva terminar uma ação para iniciar a outra, se for necessário e possível, pode-se executar ações em paralelo (ver Tabela 3).

Uma vez selecionadas e priorizadas as contramedidas, deve-se descrever os benefícios 
Quadro 6. Abordagem por processo aplicada à gestão pela produtividade.

(a)

\begin{tabular}{|c|c|c|}
\hline Ponto de entrada & Descrição & Ferramentas/fontes \\
\hline Contatos iniciais & $\begin{array}{l}\text { Apresentar a metodologia e identificar as pessoas } \\
\text { que acompanharão todo o processo. }\end{array}$ & $\begin{array}{l}\text { Reuniões para conscientização do modelo e } \\
\text { aplicabilidade da produtividade sistêmica. }\end{array}$ \\
\hline Coletar dados e informações. & $\begin{array}{l}\text { Obter as informações básicas da empresa e os } \\
\text { dados necessários para a análise quantitativa da } \\
\text { produtividade sistêmica. } \\
\text { As informações básicas referem-se a: estrutura } \\
\text { organizacional, produto(s), produto principal, } \\
\text { operações, processos, fornecedores e clientes. }\end{array}$ & $\begin{array}{l}\text { Para as informações básicas: organograma, } \\
\text { número de funcionários, relatórios anuais, } \\
\text { portfólio de produtos, fluxograma do } \\
\text { processo produtivo do(s) produto(s) ou } \\
\text { do produto principal, principais clientes e } \\
\text { fornecedores. } \\
\text { Para a análise quantitativa: dados } \\
\text { econômico-financeiros que são encontrados } \\
\text { no balanço patrimonial, demonstrativos de } \\
\text { resultados, demonstrativos de custos e outros } \\
\text { relatórios que a empresa utiliza. }\end{array}$ \\
\hline
\end{tabular}

Análise dos cinco fatores (fator gestão, fator humano, fator meios de produção, fator inventários e fator recursos naturais) e do referencial de distribuição da produtividade sistêmica. Essa análise deve considerar a tendência de pelo menos três anos (periodo fiscal).

Discriminação dos principais pontos levantados através do resultado da análise quantitativa.

Análise qualitativa Realização das entrevistas para reforçar as evidências coletadas.
Medição rápida da produtividade sistêmica.

Medição completa da produtividade sistêmica.

Desdobramento dos indicadores da produtividade sistêmica.

Visita ao chão de fábrica (observação dos postos de trabalho); fotos; estudo de leiaute; amostragem de trabalho (work sampling) e aplicação de ferramentas da qualidade como fluxograma, Pareto, matriz urgência/ viabilidade.

(b)

\begin{tabular}{cl}
\hline Procedimento & Descrição \\
\hline Cruzamento dos dados & $\begin{array}{l}\text { Relacionar os dados quantitativos aos qualitativos, } \\
\text { para uma análise conjunta. }\end{array}$
\end{tabular}

Identificar os pontos fortes e passíveis de melhoria.

Detalhamento dos problemas

Priorização dos problemas
Determinar quais fatores estão influenciando de maneira positiva ou negativa os resultados da empresa.

Descrição detalhada dos problemas, com o objetivo de desenvolver uma especificação detalhada.

Dadas as especificações dos problemas, pode-se desenvolver um processo de priorização.

\section{Ferramentas/fontes}

Planilha de cruzamento das informações quantitativas com as qualitativas, obtendo uma única lista unificada de problemas a serem trabalhados.

Matriz de priorização dos cinco fatores (fator gestão, fator humano, fator meios de produção, fator inventários e fator recursos naturais) e referencial de distribuição da produtividade sistêmica.

Árvore de problemas

Ferramentas da qualidade como fluxograma, Pareto, diagrama de causa e efeito e folha de verificação.

Pareto, diagrama de causa e efeito, matriz de priorização (AHP), desdobramento dos indicadores da produtividade sistêmica. Teoria das restrições (Theory of Constrains - TOC).

(c)

\begin{tabular}{|c|c|c|}
\hline Participação & Descrição & Ferramentas/fontes \\
\hline Estabelecer a estratégia de ação. & $\begin{array}{l}\text { A estratégia de ação deve: ser desenvolvida de forma } \\
\text { sistêmica, envolvendo a integração entre todos os } \\
\text { fatores e referenciais; possuir diferentes soluções, } \\
\text { a fim de que os envolvidos possam examinar as } \\
\text { vantagens e desvantagens, a efetividade e os custos } \\
\text { associados; apresentar a solução ou proposta de } \\
\text { consenso entre todos os envolvidos. }\end{array}$ & $\begin{array}{l}\text { As ferramentas utilizadas dependem da } \\
\text { análise e da priorização e estão associadas } \\
\text { aos fatores e referenciais da produtividade } \\
\text { sistêmica. Não existe restrição quanto à } \\
\text { utilização de ferramentas ou técnicas, as } \\
\text { quais dependem das competências do grupo } \\
\text { de trabalho. Todavia, o único cuidado } \\
\text { a ser tomado é no sentido de se aplicar } \\
\text { ferramentas que possam trazer resultados } \\
\text { sistêmicos e que sejam coerentes com o } \\
\text { conceito de produtividade sistêmica. }\end{array}$ \\
\hline $\begin{array}{l}\text { Estabelecer o plano de ação, metas, } \\
\text { prazos e responsabilidades. }\end{array}$ & $\begin{array}{l}\text { Após a definição da estratégia de ação, deverão } \\
\text { ser definidos de forma sistemática: as metas, os } \\
\text { prazos, as responsabilidades, os itens de controle e } \\
\text { as verificações. }\end{array}$ & $\begin{array}{l}\text { Cronograma. } \\
\text { Aplicação do 5W 2H (what, why, who, when, } \\
\text { where, how, how much). } \\
\text { Indicadores da produtividade sistêmica. }\end{array}$ \\
\hline
\end{tabular}


Quadro 6. Continuação...

\begin{tabular}{lll}
\hline \multicolumn{1}{c}{ Participação } & \multicolumn{1}{c}{ Descrição } & \multicolumn{1}{c}{ Ferramentas/fontes } \\
\hline & Executar o plano de ação de acordo com o & Acompanhamento in loco; \\
lmplementar as mudanças e melhorias & cronograma. & Acompanhamento do cronograma; \\
definidas. & Registrar todos os resultados. & Reuniões para ajustes/ discussões; \\
& Treinar todas as pessoas envolvidas na ação. & Treinamentos complementares.
\end{tabular}

(d)

\begin{tabular}{|c|c|c|}
\hline Gestão do projeto & Descrição & Ferramentas/fontes \\
\hline $\begin{array}{l}\text { Monitorar as mudanças em andamento } \\
\text { ou já concluídas (verificar se as } \\
\text { mudanças foram efetivas e suficientes). }\end{array}$ & $\begin{array}{l}\text { Verificar se as mudanças foram aplicadas de forma } \\
\text { coerente e se apresentaram os resultados esperados. } \\
\text { Listar os efeitos secundários positivos e negativos } \\
\text { verificados. }\end{array}$ & $\begin{array}{l}\text { Coleta de dados para verificação/ medição; } \\
\text { Folha de verificação. }\end{array}$ \\
\hline $\begin{array}{l}\text { Aplicar nova medição dos indicadores } \\
\text { da produtividade sistêmica. }\end{array}$ & $\begin{array}{l}\text { Aplicar nova análise quantitativa e qualitativa } \\
\text { para verificar o desempenho atual dos fatores e } \\
\text { referenciais. }\end{array}$ & $\begin{array}{l}\text { Medição rápida da produtividade sistêmica; } \\
\text { Medição completa da produtividade } \\
\text { sistêmica; } \\
\text { Desdobramento dos indicadores da } \\
\text { produtividade sistêmica; } \\
\text { Análise qualitativa. }\end{array}$ \\
\hline Comparar o planejado com o realizado. & $\begin{array}{l}\text { Verificar se os indicadores e/ou dados apresentaram } \\
\text { melhores resultados. }\end{array}$ & $\begin{array}{l}\text { Análise de tendência dos indicadores da } \\
\text { produtividade sistêmica; } \\
\text { Comparação dos dados ou indicadores } \\
\text { qualitativos. }\end{array}$ \\
\hline Analisar os resultados obtidos. & Proceder a nova análise da produtividade sistêmica. & $\begin{array}{l}\text { Análise dos gráficos e dos resultados } \\
\text { quantitativos e qualitativos. }\end{array}$ \\
\hline $\begin{array}{l}\text { Verificar se houve melhorias de forma } \\
\text { sistêmica. }\end{array}$ & $\begin{array}{l}\text { Caso o resultado não tenha sido satisfatório, verificar } \\
\text { se todas as ações foram executadas de acordo com o } \\
\text { plano de ação. }\end{array}$ & $\begin{array}{l}\text { Se a ação foi efetiva, passar para a } \\
\text { atividade } 8.1 \text {, se não, retornar à atividade } 6.1 \text {. }\end{array}$ \\
\hline $\begin{array}{l}\text { Padronizar as melhorias implementadas } \\
\text { a fim de evitar a sua reincidência. }\end{array}$ & $\begin{array}{l}\text { Estabelecer novos padrões a serem seguidos. } \\
\text { Comunicar a todas as áreas envolvidas a existência } \\
\text { de novos padrões ou alterações promovidas. } \\
\text { Certificar-se de que todas as pessoas estão aptas a } \\
\text { executar os novos padrões. } \\
\text { Verificar se os padrões estão sendo colocados em } \\
\text { prática. }\end{array}$ & $\begin{array}{l}\text { Manual da qualidade; } \\
\text { Comunicações internas; } \\
\text { Reuniões; } \\
\text { Palestras; } \\
\text { Treinamentos; } \\
\text { Acompanhamentos; } \\
\text { Verificações in loco; } \\
\text { Auditorias Internas. }\end{array}$ \\
\hline $\begin{array}{l}\text { ldentificar novos problemas e } \\
\text { oportunidades de melhoria. }\end{array}$ & $\begin{array}{l}\text { Avaliar o que e quanto não foi realizado, bem como } \\
\text { os resultados acima do esperado. } \\
\text { ldentificar as oportunidades de melhoria. }\end{array}$ & $\begin{array}{l}\text { Demonstrações gráficas; } \\
\text { Reuniões; } \\
\text { Relatórios. }\end{array}$ \\
\hline Aplicar um novo PDCA & $\begin{array}{l}\text { Reavaliar os itens pendentes e/ou as oportunidades } \\
\text { de melhoria, organizando-os para novo ciclo de } \\
\text { melhoria da produtividade sistêmica. }\end{array}$ & $\begin{array}{l}\text { PDCA para a gestão pela produtividade } \\
\text { sistêmica. }\end{array}$ \\
\hline
\end{tabular}

Fonte: Os autores (2011).

que essas contramedidas irão proporcionar na sua implantação.

Cabe destacar que o processo desenvolvido é fruto de uma cooperação Brasil-Japão e que a contribuição deste trabalho está em discutir a sistematização desse modelo, principalmente no que se refere ao seu uso e aplicação (INSTITUTO..., 2004).

Dadas as principais características do processo de implantação da gestão pela produtividade sistêmica, pode-se trabalhar o seu refinamento.

\section{Refinando o processo}

A partir do processo desenvolvido, foram conduzidas entrevistas com consultores técnicos visando o seu refinamento, objetivando discutir a sua implantação e sistematização via abordagem de processos de Cambridge.
Quadro 7. Priorização dos fatores.

\begin{tabular}{cc}
\hline Pontos & Importância \\
\hline 9 & Muito superior \\
7 & Bastante superior \\
5 & Superior \\
3 & Pouco superior \\
1 & Equivalente \\
$1 / 3$ & Pouco inferior \\
$1 / 5$ & Inferior \\
$1 / 7$ & Bastante inferior \\
$1 / 9$ & Muito inferior \\
\hline
\end{tabular}

Fonte: Os autores (2011) e Sarkis (2003).

Foram entrevistados três consultores técnicos. Os entrevistados são especialistas nas seguintes áreas: estratégia de manufatura, avaliação/desenvolvimento de sistemas de qualidade e produtividade e gestão de processos. As entrevistas tiveram em média a duração de $1 \mathrm{~h} 30$, sendo que os entrevistados receberam o 
roteiro com pelo menos duas semanas de antecedência. As entrevistas foram desenvolvidas de forma sequencial para sempre aproveitar o conhecimento gerado e se desdobraram em um período de cerca de dois meses.

Foram empregadas entrevistas semiestruturadas, seguindo um roteiro que cobre os seguintes tópicos: objetivos do trabalho e do processo, lógica do processo, número de etapas e atividades, folhas de tarefa e procedimentos operacionais, tempo de aplicação, pessoas envolvidas e avaliação do processo. 0 Quadro 8 sumariza as contribuições das entrevistas na revisão do processo.

Apresentadas algumas das observações que contribuíram para o refinamento do processo, pode-se ilustrar a aplicação do processo de mensuração

Tabela 1. Exemplo de priorização.

\begin{tabular}{ccccccccc}
\hline & $\mathrm{F}_{\mathrm{G}}$ & $\mathrm{F}_{\mathrm{H}}$ & $\mathrm{F}_{\mathrm{MP}}$ & $\mathrm{F}_{1}$ & $\mathrm{~F}_{\mathrm{RN}}$ & Média geométrica & Peso & Prior. \\
\hline $\mathrm{F}_{\mathrm{G}}$ & 1 & 5 & 3 & 7 & 7 & $\sqrt[5]{1^{*} 5^{*} 3^{*} 7^{*} 7}=3,74$ & $53,97 \%$ & $1^{\circ}$ \\
$\mathrm{F}_{\mathrm{H}}$ & $1 / 5$ & 1 & $1 / 3$ & 5 & 5 & $\sqrt[5]{(1 / 5)^{*} 1^{*}(1 / 3) * 5^{*} 5}=1,11$ & $16,02 \%$ & $2^{\circ}$ \\
$\mathrm{F}_{\mathrm{MP}}$ & $1 / 3$ & 3 & 1 & $1 / 3$ & 5 & $\sqrt[5]{(1 / 3)^{*} 3^{*} 1^{*}(1 / 3) * 5}=1,11$ & $16,02 \%$ & $2^{\circ}$ \\
$\mathrm{F}_{1}$ & $1 / 7$ & $1 / 5$ & 3 & 1 & 1 & $\sqrt[5]{(1 / 7)^{*}(1 / 5)^{*} 3^{*} 1^{*} 1}=0,61$ & $8,8 \%$ & $4^{\circ}$ \\
$\mathrm{F}_{\mathrm{RN}}$ & $1 / 7$ & $1 / 5$ & $1 / 5$ & 1 & 1 & $\sqrt[5]{(1 / 7)^{*}(1 / 5)^{*}(1 / 5)^{*} 1^{*}}=0,36$ & $5,19 \%$ & $5^{\circ}$ \\
\hline
\end{tabular}

Fonte: Os autores (2011).

Tabela 2. Priorização das contramedidas.

\begin{tabular}{cccc}
\hline Pontos & Importância & Emergência & Viabilidade \\
\hline 1 & Não é importante & Pode aguardar & Não é viável \\
3 & Pouco importante & Pouco prioritária & Pouco viável \\
5 & Importante & Prioritária & Viável \\
7 & Muito importante & Muito urgente & Muito viável \\
9 & Estritamente importante & Ação imediata & Estritamente viável \\
\hline
\end{tabular}

Fonte: Os autores (2011).

Tabela 3. Exemplo de pontuação para as contramedidas.

\begin{tabular}{ccccc}
\hline Contramedidas & Importância & Emergência & Viabilidade & TOTAL \\
\hline Ação 1 & 3 & 5 & 7 & $3+5+7=15$ \\
Ação 2 & 9 & 9 & 7 & $9+9+7=25$ \\
Ação 3 & 7 & 5 & 5 & $7+5+5=17$ \\
\hline
\end{tabular}

Fonte: Os autores (2011).

Quadro 8. Principais contribuições das entrevistas.

\section{Contribuições}

Facilidade na aplicação da metodologia, contudo as informações de caráter financeiro e contábil devem ser melhor trabalhadas junto aos responsáveis pelas organizações.

0 tempo de aplicação e proposta de ações deve ser de cinco dias úteis, porque as organizações, de um modo geral, têm pressa em saber as respostas.

0 envolvimento das pessoas-chave da organização exige uma programação muito rígida, principalmente nas atividades que envolvem entrevistas e coleta de informações.

Existe uma lógica na estrutura apresentada mas há necessidade de um entendimento e engajamento maior por parte das empresas, porque alguns entraves podem ser criados no início do processo, em que informações econômico-financeiras são necessárias.

0 que foi chamado de medição rápida da produtividade é uma ferramenta que foi muito elogiada pelos entrevistados. Essa atividade agiliza a busca de informações e ao mesmo tempo explica que tipo de indicador é necessário e como desenvolvê-los.

\section{Comentário}

Existem dados na etapa de diagnóstico que devem ser disponibilizados sob pena de não se ter continuidade no trabalho. Há necessidade de se estabelecer um contrato de confidencialidade.

0 objetivo da aplicação da metodologia do process approach é exatamente para agilizar o processo.

Pelo fato de o prazo para levantamento das informações ser determinado e de as entrevistas fazerem parte do processo, o seguimento de um cronograma e o uso de ferramentas de gestão de projetos e do process approach é fundamental.

0 reflexo disso pode ser o atraso ou até mesmo conclusões erradas sobre as características da empresa, o que prejudica a aplicação do processo. Há necessidade de se enfatizar novamente a responsabilidade e o sigilo no uso das informações.

Essa ferramenta foi criada exatamente para agilizar o processo de coleta e pode ser utilizada também através da internet com total segurança. Também possibilita desenvolver uma compreensão sobre a abrangência de uso da metodologia. 
da produtividade sistêmica através de um caso de simulação. A seguir apresenta-se uma seleção de resultados da aplicação do processo desenvolvido. Para o estudo de simulação utilizaram-se os dados reais de uma empresa de manufatura de produtos cerâmicos para a construção civil média, com cerca de 130 colaboradores diretos e $\mathrm{R} \$ 3,5$ milhões de faturamento médio anual.

Destaca-se que o processo é descrito no Quadro 5 e "operacionalizado" pelo Quadro 6, observando-se os quatro aspectos que definem a abordagem por processos de Cambridge. A seguir são selecionados alguns procedimentos que definem a gestão pela produtividade sistêmica. As informações produzidas são de caráter ilustrativo e fazem parte de um exercício no uso de procedimentos e técnicas que definem o processo de gestão pela produtividade sistêmica (Quadro 5) bem como a sua sistematização via process approach (Quadro 6).

As Tabelas 4 e 5 apresentam os resultados da medição rápida de produtividade, conforme estabelecido na atividade 1.3 do Quadro 6.

Da Tabela 4 destaca-se a determinação ou cálculo do valor adicionado que constitui uma referência de avaliação para a produtividade sistêmica. Na realidade, ele define a riqueza gerada em termos absolutos e que será relativizada nos diferentes aspectos que definem a produtividade sistêmica, conforme parcialmente ilustrado na Tabela 5.

A visão sistêmica da produtividade procura relacioná-la a diferentes dimensões que intervêm na criação de valor. Essas dimensões estão representadas

Tabela 4. Medição rápida da produtividade: dados patrimoniais.

\begin{tabular}{|c|c|c|c|c|c|}
\hline \multirow{2}{*}{ Dados patrimoniais } & \multicolumn{3}{|c|}{ Ano fiscal } & \multicolumn{2}{|c|}{ \% de crescimento } \\
\hline & Ano 1 & Ano 2 & Ano 3 & Ano 2 & Ano 3 \\
\hline Despesas com pessoal & $700.851,94$ & $739.099,43$ & $686.874,42$ & $5 \%$ & $-2 \%$ \\
\hline Despesas financeiras & $1.929,49$ & $2.356,23$ & 926,49 & $22 \%$ & $-52 \%$ \\
\hline Impostos e taxas & $159.676,69$ & $147.917,72$ & $168.146,81$ & $-7 \%$ & $5 \%$ \\
\hline Despesas com aluguel & & & & - & - \\
\hline Depreciação & $419.725,36$ & $402.733,67$ & $809.353,77$ & $-4 \%$ & $93 \%$ \\
\hline Lucro líquido após IR & $2.327 .150,44$ & $2.282 .350,33$ & $1.721 .445,95$ & $-2 \%$ & $-26 \%$ \\
\hline Valor adicionado & $3.609 .333,91$ & $3.574 .457,38$ & $3.386 .747,45$ & $-1 \%$ & $-6 \%$ \\
\hline Vendas líquidas & $2.647 .743,02$ & $2.770 .107,75$ & $2.591 .043,57$ & $5 \%$ & $-2 \%$ \\
\hline Número de empregados & 82 & 88 & 96 & $7 \%$ & $17 \%$ \\
\hline Ativo total & $6.109 .959,37$ & $7.850 .715,89$ & $8.005 .918,26$ & $28 \%$ & $31 \%$ \\
\hline Imobilizado & $3.356 .812,88$ & $4.671 .178,72$ & $5.230 .710,00$ & $39 \%$ & $56 \%$ \\
\hline
\end{tabular}

Fonte: Os autores (2011).

Tabela 5. Medição rápida da produtividade: fatores e referenciais relacionados.

\begin{tabular}{|c|c|c|c|c|}
\hline & Fórmula & Ano 1 & Ano 2 & Ano 3 \\
\hline \multicolumn{5}{|c|}{ Indicadores do fator gestão } \\
\hline$\%$ valor adicionado/Vendas & Valor adicionado/Vendas & $136 \%$ & $129 \%$ & $131 \%$ \\
\hline Produtividade do capital & Valor adicionado/Ativo total & 0,59 & 0,46 & 0,42 \\
\hline Giro do ativo & Vendas/Ativo & 0,43 & 0,35 & 0,32 \\
\hline Rentabilidade do ativo & Lucro líquido/Ativo total & 0,38 & 0,29 & 0,22 \\
\hline Margem liquida & & 0,88 & 0,82 & 0,66 \\
\hline \multicolumn{5}{|c|}{ Indicadores do fator humano } \\
\hline Produtividade do trabalho & Valor adicionado/Número de empregados & $44.016,27$ & $40.618,83$ & $35.278,62$ \\
\hline Vendas/Empregado & Vendas líquidas/Número de empregados & $32.289,55$ & $31.478,50$ & $26.990,04$ \\
\hline $\begin{array}{c}\text { Contribuição das despesas com pessoal no } \\
\text { valor adicionado }\end{array}$ & Valor adicionado/Despesas com pessoal & 5,15 & 4,84 & 4,93 \\
\hline Intensidade do capital & Imobilizado/Número de empregados & $40.936,74$ & $53.081,58$ & $54.486,56$ \\
\hline \multicolumn{5}{|c|}{ Indicadores do fator meios de produção } \\
\hline Produtividade do imobilizado & Valor adicionado/lmobilizado & 1,08 & 0,77 & 0,65 \\
\hline Contribuição do imobilizado nas vendas & Vendas/1mobilizado & 0,79 & 0,59 & 0,50 \\
\hline \multicolumn{5}{|c|}{ Indicadores do fator distribuição do VA } \\
\hline Participação trabalhador valor adicionado & Despesas com pessoal/Valor adicionado & $19 \%$ & $21 \%$ & $20 \%$ \\
\hline Participação investidor valor adicionado & Lucro líquido/Valor adicionado & $64 \%$ & $64 \%$ & $51 \%$ \\
\hline
\end{tabular}

Fonte: Os autores (2011). 
Quadro 9. Análise qualitativa.

Indicadores da alta direção

A empresa não tem definida formalmente sua política, missão e visão, porém ao final de cada ano é feita uma reunião entre a presidência e os encarregados para a definição de metas a serem alcançadas no ano seguinte, bem como é feito o

Planejamento acompanhamento das metas realizadas no ano que se encerra.

estratégico Essas metas são de produção, faturamento e ampliação da empresa. A Unidade 11 começou a operar há seis meses, produzindo blocos, mas foi planejada para fabricar telhas.

Meta atual de produção na Unidade 1 e 11: 5 milhões de peças/mês, traçada com base na capacidade produtiva dos equipamentos.

Planejamento São realizadas reuniões mensais entre presidente, encarregado e pessoal de cada área para discussão dos problemas e definição de operacional soluções. Essas reuniões são registradas em atas, porém são transmitidas para todos os envolvidos verbalmente.

Principais Os principais produtos são: blocos cerâmicos (vedação e estrutural), lajotas pré-moldadas, laminados, elementos calha e produtos elementos vazados.

A maioria dos clientes (70\%) estão localizados no estado no qual está sediada a empresa, sendo esse percentual dividido na seguinte proporção: 50\% são depósitos de revendedores, 15\% são pessoas físicas e 5\% são construtoras.

Principais Os clientes sediados no estado vizinho representam 30\% do total e estão divididos na seguinte proporção: 15\% são clientes depósitos de revendedores, 10\% são pessoas físicas e 5\% são construtoras.

Atualmente, a empresa pretende aumentar a venda para pessoas físicas do estado vizinho, sendo que aceita pedidos a partir de um volume mínimo de meio caminhão.

Sucesso da 0 sucesso da empresa é atribuído à dedicação da equipe, à dedicação exclusiva do presidente a essa atividade, aos empresa investimentos realizados em equipamentos, que superam a média dos concorrentes, e aos preços praticados.

Indicadores da área de produção

\section{Capacidade de produção \\ A capacidade produtiva da Unidade 1 é de 4 milhões de peças/mês e da Unidade 11 é de 2 milhões de peças/mês.}

Tempo de produção

Tempo entre pedido e entreg

0 ciclo de produção é estimado em cinco dias, sendo que a estocagem da produção verde e a secagem consomem mais três dias. A matéria-prima precisa passar por um processo de secagem ao ar livre por um período aproximado de seis meses.

Normalmente é disponibilizada para o setor de vendas a produção da semana anterior, sendo que antes da atividade da Unidade 11 não se conseguia atender a demanda.

Atualmente, existe um pequeno estoque de produtos.

A empresa aceita pedido de produtos especiais e os fabrica principalmente na Unidade 11, porém a Unidade 1 também atende

Pedidos especiais a esse tipo de pedido. Esses pedidos devem ser preferencialmente acima de 50 mil peças.

Não são desenvolvidos protótipos para os produtos especiais.

A empresa não tem contrato de manutenção de máquinas e equipamentos, sendo a manutenção periódica realizada aos sábados e por funcionários treinados na própria fábrica dos equipamentos.

Manutenção $\quad$ Os fornos funcionam 24 horas/dia e não é feita neles nenhuma manutenção. Não existe atraso na produção por causa de problemas com equipamentos.

\section{Indicadores da área financeira}

A empresa tem o seguinte planejamento financeiro: meta de faturamento, meta de investimento anual, meta de redução de custos, o que vai investir em cada setor - contratação de pessoas, tecnologia, capacitação da mão de obra, em que vai Planejamento aplicar mais, em que vai aplicar menos, quanto vai aplicar etc. lsso é definido anualmente em reunião com as diretorias. Existem metas gerenciais estabelecidas. Há planejamento de vendas, cálculo de produção, avaliação do mercado e região. Não foi declarado a existência de metas de liquidez corrente.

A empresa adota a seguinte estratégia para atingir o ponto de equilíbrio Receita/despesas: diminuir despesas e aumentar o faturamento - aumento da receita. A principal estratégia é aumentar as vendas.

A redução de custos é definida pela mudança de processos. Exemplo: mudança de lenha para eucaliptos e pinus, com maior rendimento na queima. Inovação e aprimoramento do processo, com uso de maquinário novo e lançamento de novos Ponto de produtos como, por exemplo, o bloco de seis furos com tamanho especial utilizado no interior do estado.

equilibrio A empresa procura obter melhores preços e diversificar os produtos para atingir novos mercados.

Uma vez que os dados contábeis da empresa não refletem adequadamente a realidade, a empresa não os utiliza para fazer análises de redução de custos.

0 preço de venda dos produtos é definido em função do mercado, uma vez que há muitos concorrentes. É o que "o mercado paga". É feita a adequação dos custos ao preço de venda.

A situação predominante do saldo do fluxo de caixa da empresa é positiva.

A relação entre entradas e saídas, ou seja, valores a receber e valores a pagar é positiva, isto é, os valores a pagar são menores que os valores a receber.

A empresa possui uma política de investimento em curto, médio ou longo prazo. Como exemplo, nesse momento estão

Fluxo de caixa sendo feitas reformas para ampliação do escritório, foram feitos investimentos em informática, em caminhões ("para chegar mais longe") e em uma unidade produtiva para produção de telha branca.

Existe sempre um controle do capital de giro para dar prazos de pagamento aos clientes e, para o fornecedor, uma reserva de itens - compra de argila no verão e lenha para estocar para o inverno.

A empresa reinveste anualmente grande parte de seu faturamento (não foi declarado quanto do faturamento em termos de percentual) em pessoas, informática e ampliação da fábrica.

\section{Indicadores da área comercial}

Mercado A faixa de mercado em que a empresa atua é a de atendimento a pequenas e médias empresas da cadeia da construção civil na área de comércio - revenda, num percentual de 50\% de pequenas a 50\% de médias.

Como estratégia de marketing, a empresa pretende pesquisar o mercado onde vende, conhecer melhor as empresas que revendem seus produtos e lançar uma forte campanha junto aos pedreiros, de modo a cadastrá-los e dar uma participação financeira e prêmios para quem mais divulgar e indicar para compra os produtos da empresa.

Marketing e Atualização de cadastro/clientes.

produção A linha de produção é definida em função do mercado. Assim, existe a possibilidade - e já aconteceram mudanças na linha de produtos (dimensões e detalhes das especificações técnicas da forma) em função de uma forte demanda de determinado cliente. A empresa procura acompanhar a satisfação dos clientes com seus produtos e serviços apenas de maneira informal. 
nos fatores de gestão, humano, meios de produção e distribuição do valor adicionado. Tais fatores organizam as informações que constam da Tabela 5.

0 Quadro 9 apresenta uma seleção de indicadores utilizados na análise qualitativa desenvolvida a partir de entrevistas realizadas com a alta direção da empresa, a área de produção, a área financeira e a área comercial (ver atividade 1.4 do Quadro 6).

0 extrato da avaliação qualitativa apresentada no Quadro 9 contribui diretamente para a contextualização do diagnóstico, ou seja, define um escopo de atividades e das informações sobre o desempenho organizacional. Tais elementos definem um pano de fundo para o estudo da produtividade sistêmica.

De acordo com a atividade 2.2 do Quadro 6 é possível, a partir da análise desenvolvida na etapa de diagnóstico, identificar os pontos fortes e pontos passíveis de melhoria. 0 Quadro 10 apresenta uma seleção de tais pontos.

A Tabela 6 ilustra a priorização dos fatores, em que se destaca a priorização do fator gestão.

0 exercício cujo resultado é apresentado na Tabela 6 define os fatores prioritários que resultam na definição da produtividade sistêmica. A priorização reflete a contribuição relativa de cada fator no caso estudado.

A Tabela 7 apresenta a priorização das contramedidas, onde "estruturar setores da empresa definindo cargos e funções” tem a maior prioridade.

A contramedida define uma ação e a matriz de priorização, seu conjunto. Esse conjunto de ações e a sua priorização definem um plano de ação baseado na gestão pela produtividade sistêmica. Tem-se, portanto, um sistema de gestão fundamentado em

Quadro 10. Pontos fortes e pontos passíveis de melhoria.

\begin{tabular}{|c|c|c|}
\hline Fatores relacionados & Pontos fortes & Pontos passiveis de melhoria \\
\hline Fator recursos naturais & $\begin{array}{l}\text { Utilização do resíduo de pinho de } \\
\text { reflorestamento como lenha. }\end{array}$ & $\begin{array}{l}\text { Falta de medição da capacidade de exploração das jazidas. } \\
\text { Degradação ambiental devido à exploração de jazidas. } \\
\text { Falta de controle da emissão dos gases de queima. } \\
\text { Falta de conscientização ambiental dos envolvidos com a } \\
\text { exploração de jazidas. } \\
\text { Perda de calor nos fornos. }\end{array}$ \\
\hline Fator inventários & $\begin{array}{l}\text { Tamanho da área da empresa. } \\
\text { Baixo estoque de produto. } \\
\text { Alto estoque de matéria-prima. } \\
\text { Disponibilidade de matéria-prima. } \\
\text { Maquinário. } \\
\text { Transporte. }\end{array}$ & Baixa contribuição do inventário nas vendas. \\
\hline $\begin{array}{l}\text { Fator meios de } \\
\text { produção }\end{array}$ & $\begin{array}{l}\text { Controle de qualidade do produto. } \\
\text { Queima dos fornos. } \\
\text { Lay out da área de produção. } \\
\text { Carregamento facilitado pelo leiaute de } \\
\text { produção. } \\
\text { Limpeza. } \\
\text { Rotina. } \\
\text { Acompanhamento da produção diária. } \\
\text { Disponibilidade e qualidade da matéria-prima. } \\
\text { Uso de dois laminadores na produção, } \\
\text { promovendo melhor plasticidade do material. } \\
\text { Área de secagem. } \\
\text { Flexibilidade de produção. } \\
\text { Baixo índice de perdas do produto. }\end{array}$ & $\begin{array}{l}\text { Desperdício de energia e de tempo no final da produção da } \\
\text { máquina. } \\
\text { Retrabalho na fase final da produção verde. } \\
\text { Falta de uso de equipamentos de proteção individual. } \\
\text { Capacidade produtiva ociosa. } \\
\text { Não atendimento à normatização. } \\
\text { Baixa contribuição do imobilizado nas vendas. } \\
\text { Otimização do leiaute da máquina para minimizar o retrabalho. } \\
\text { Minimizar as perdas de calor nos fornos. }\end{array}$ \\
\hline Fator humano & $\begin{array}{l}\text { Baixa rotatividade. } \\
\text { Equipe reduzida. } \\
\text { Equipe motivada. } \\
\text { Limpeza da área de vivência. } \\
\text { Baixo índice de acidentes de trabalho. }\end{array}$ & $\begin{array}{l}\text { Falta de uso de equipamentos de proteção individual. } \\
\text { Ambiente insalubre nos fornos. }\end{array}$ \\
\hline Fator gestão & $\begin{array}{l}\text { Investimento para desenvolvimento. } \\
\text { Solidez financeira. } \\
\text { Fluxo de caixa. }\end{array}$ & $\begin{array}{l}\text { Falta de planejamento estratégico. } \\
\text { Falta de planejamento financeiro. } \\
\text { Falta de sistema de gestão. } \\
\text { Falta de conhecimento do mercado. } \\
\text { Estrutura organizacional. } \\
\text { Baixa rentabilidade do ativo. } \\
\text { Queda do lucro líquido sobre as vendas líquidas. } \\
\text { Baixo volume de vendas em relação ao ativo. }\end{array}$ \\
\hline Referencial distribuição & $\begin{array}{l}\text { Manutenção da participação dos empregados } \\
\text { no valor adicionado. }\end{array}$ & $\begin{array}{l}\text { Alta participação da depreciação no valor adicionado. } \\
\text { Falta de estratégia de distribuição do valor adicionado. }\end{array}$ \\
\hline Referencial comparação & Tradição no mercado. & Desconhecimento de referencial de comparação. \\
\hline
\end{tabular}


Tabela 6. Priorização dos fatores utilizando a técnica AHP.

\begin{tabular}{|c|c|c|c|c|c|c|c|c|}
\hline & $F_{G}$ & $\mathrm{~F}_{\mathrm{H}}$ & $\mathrm{F}_{\mathrm{MP}}$ & $F_{1}$ & $\mathrm{~F}_{\mathrm{RN}}$ & Med. & Peso & Priorização \\
\hline $\mathrm{F}_{\mathrm{G}}$ & 1 & 5 & 5 & 3 & 5 & 3,27 & 0,50 & $1^{\circ}$ \\
\hline $\mathrm{F}_{\mathrm{H}}$ & $1 / 5$ & 1 & 1 & 3 & 3 & 1,12 & 0,17 & $2^{\circ}$ \\
\hline $\mathrm{F}_{\mathrm{MP}}$ & $1 / 5$ & 1 & 1 & 3 & 3 & 1,12 & 0,17 & $2^{\circ}$ \\
\hline $\mathrm{F}_{1}$ & $1 / 3$ & $1 / 3$ & $1 / 3$ & 1 & 1 & 0,52 & 0,08 & $3^{\circ}$ \\
\hline $\mathrm{F}_{\mathrm{RN}}$ & $1 / 5$ & $1 / 3$ & $1 / 3$ & 1 & 1 & $\begin{array}{l}0,47 \\
6,51\end{array}$ & 0,07 & $4^{\circ}$ \\
\hline $\mathrm{Cl}$ & 0,08 & & $\mathrm{CR}$ & $7 \%$ & & & & \\
\hline
\end{tabular}

Cl deve ser menor que 0,1 ou, no máximo, 0,15. CR deve ser inferior a 10\%. Fonte: Os autores (2011).

Tabela 7. Priorização das contramedidas.

\begin{tabular}{|c|c|c|c|c|c|c|}
\hline \multicolumn{7}{|c|}{ Matriz de priorização de contramedidas } \\
\hline & Contramedidas & Importância & Emergência & Viabilidade & Total & Prioridade \\
\hline 1 & Planejamento estratégico & 5 & 3 & 5 & 13 & $3^{\circ}$ \\
\hline 2 & $\begin{array}{l}\text { Estruturar os setores da empresa definindo } \\
\text { cargos e funções }\end{array}$ & 9 & 7 & 9 & 25 & $1^{\circ}$ \\
\hline 3 & $\begin{array}{l}\text { Aumentar a rentabilidade do ativo } \\
\text { (aumento das vendas) }\end{array}$ & 9 & 5 & 5 & 19 & $2^{\circ}$ \\
\hline 4 & Planejamento financeiro & 5 & 3 & 5 & 13 & $3^{\circ}$ \\
\hline
\end{tabular}

Fonte: Os autores (2011).

medidas e ações que contribuem sistematicamente para a melhoria da produtividade sistêmica.

A abordagem de Cambridge teve um papel fundamental na organização de procedimentos, na definição de uma componente de coordenação e na criação de um espaço de participação. Tais elementos animaram o projeto de pesquisa e contribuíram para a gênese coletiva de um sistema de gestão estratégica pela produtividade sistêmica.

Os resultados apresentados ilustram a aplicação de alguns procedimentos para a apuração de uma medida para a produtividade sistêmica, bem como as ações para a sua melhoria.

\section{Conclusão}

A adoção da abordagem por processos de Cambridge facilita o entendimento e a implementação sequenciada da gestão pela produtividade sistêmica. A adequação dessa metodologia, objetivo deste trabalho de pesquisa, se mostrou de fato mais ágil em relação à forma usual de aplicação.

O desenvolvimento do processo contribuiu significativamente para uma análise comparativa, ou seja, tal construção permitiu avaliar as práticas adotadas, dada a sua propriedade de sistematizar a análise da produtividade. Muito embora o caso usado para ilustrar a aplicação restrinja a análise completa do uso das técnicas e procedimentos, ele nos dá pistas úteis quanto à usabilidade e utilidade do processo proposto.

$\mathrm{Na}$ aplicação prática da metodologia, foi comentado pelos entrevistados que há necessidade de instrumentos que dêem coerência e consistência aos procedimentos, facilitando a condução do processo, visto que o comportamento dos dirigentes é de desconfiança.

A necessidade de um único indicador da produtividade sistêmica exige a realização de um número significativo de aplicações da metodologia a fim de se obter quantidade suficiente para poder comparar - mais uma vez fica comprovada a necessidade de uma forma rápida de medir a produtividade sistêmica.

Questões relativas à sustentabilidade das organizações devem ser objeto de estudos futuros através de um aprofundamento maior de questões como meio ambiente e responsabilidade social, buscando-se com isso ampliar ainda mais o escopo de aplicação da gestão pela produtividade sistêmica.

A aplicação prática da metodologia através da abordagem por processos de Cambridge possibilitou concluir que ainda é preciso evoluir em alguns aspectos (fatores), principalmente os relacionados ao meio ambiente e à dimensão social.

0 caso de simulação é também influenciado por fatores contingenciais como idade, porte e base tecnológica da empresa estudada. Esses elementos influenciam também os resultados de produtividade e 
em muitas situações não se encontram devidamente trabalhados. Como continuidade deste trabalho, propõe-se incorporar ao estudo um diagnóstico mais aprofundado desses fatores. No caso da simulação em questão observou-se um baixo nível de maturidade no desenvolvimento do sistema de planejamento e gestão.

A produtividade constitui a principal forma de medir a geração de riquezas em uma sociedade. Aumentos de produtividade significam não só a ampliação do valor adicionado em relação aos recursos utilizados nos processos de produção mas também a expansão e diversificação dos mercados.

\section{Referências}

ARBIX, G.; DE NEGRI, J. A. A nova competitividade da indústria e o novo empresariado: uma hipótese de trabalho. Instituto de Estudos Avançados da Universidade de São Paulo, 2005. Texto para discussão. Disponível em: <http://www.iea.usp.br/iea/glauco1.pdf>. Acesso em: 15 dez. 2006.

BOOTHBY, D.; DUFOUR, A.; TANG, J. Technology adoption, training and productivity performance. Research Policy, v. 39, n. 5, p. 650-661, 2010. http://dx.doi.org/10.1016/j. respol.2010.02.011

CHEN, L. H.; LIAW, S. Y. Investigating resource utilization and product competence to improve production management: an empirical study. International Journal of Operations \& Production Management, v. 21, n. 9, p. 1180-1194, 2001. http://dx.doi.org/10.1108/ EUM0000000005922

CHEN, L. H.; LIAW, S. Y.; CHEN, Y. S. Using financial factors to investigate productivity: an empirical study in Taiwan. Industrial Management \& Data Systems, v. 101, n. 7, p. 378-384, 2001. http://dx.doi.org/10.1108/ EUM0000000005826

CHENG, L. C.; SILVA, J. M.; LIMA, F. P. A. Desafios da qualidade e produtividade à engenharia de produção do Brasil. Produção, v. 4, n. 2, p. 127-140, 1994.

CHUNG, W. K. Benchmarking Singapore's high-TQM maturity organizations. Benchmarking: An International Journal, v. 8, n. 1, p. 8-34, 2001.

COUGHLAN, P.; COGHLAN, D. Action research for operations management. International Journal of Operations \& Production Management, v. 22, n. 2, p. 220-240, 2002. http://dx.doi.org/10.1108/01443570210417515

DEMETER, K.; CHIKÁN, A.; MATYUSZ, Z. Labour productivity change: drivers, business impact and macroeconomic moderators. International Journal of Production Economics, v. 131, n. 1, p. 215-223, 2011. http://dx.doi. org/10.1016/j.ijpe.2010.11.003

DONE, A.; VOSS, C. A.; RYTTER, N. G. Best practice interventions: short-term impact and long-term outcomes. Journal of Operations Management, v. 29, n. 5, p. 500-513, 2011. http://dx.doi.org/10.1016/j. jom.2010.11.007

GOLDRATT, E. A síndrome do palheiro, garimpando informação num oceano de dados. São Paulo: Educatur, 1992.

GOUVEA DA COSTA, S. E.; PLATTS, K. W.; FLEURY, A. C. C. Strategic selection of advanced manufacturing technologies (AMT), based on the manufacturing vision. International Journal of Computer Applications in
Technology, v. 27, n. 1, p. 12-23, 2006. http://dx.doi. org/10.1504/IJCAT.2006.010985

GRONROOS, O. C.; OJASAL, K. Service productivity towards a conceptualization of the transformation of inputs into economic results in services. Journal of Business Research, v. 57, n. 4, p. 414-423, 2004.

HAMERI, A.-P.; LEHTONEN, J.-M. Production and supply management strategies in Nordic paper mills. Scandinavian Journal of Management, v. 17, n. 3, p. 379-396, 2001. http://dx.doi.org/10.1016/S09565221(99)00042-1

HOLWEG, M. The genealogy of lean production. Journal of Operations Management, v. 25, n. 2, p. 420-437, 2007. http://dx.doi.org/10.1016/j.jom.2006.04.001

HUANG, S. H. et al. Manufacturing productivity improvement using effectiveness metrics and simulation analysis. International Journal of Production Research, v. 41, n. 3, p. 513-527, 2003. http://dx.doi. org/10.1080/0020754021000042391

INSTITUTO BRASILEIRO DA QUALIDADE E PRODUTIVIDADE - IBQP. Diagnóstico da produtividade sistêmica. Curitiba: IBQP, 2004. Programa de capacitação de agentes da produtividade - módulo IV.

JOEL, G.; DANIEL, B. Blurring the boundary: convergence of factory and service processes. Journal of Manufacturing Technology Management, v. 21, n. 3, p. 341-354, 2010. http://dx.doi.org/10.1108/17410381011024322

KARMAKAR, U. S.; APTE, U. M. Operations management in the information economy: Information products, processes, and chains. Journal of Operations Management, v. 25, n. 2, p. 438-453, 2007. http://dx.doi.org/10.1016/j. jom.2006.11.001

KUMBHAKAR, S. C. Productivity measurement: a profit function approach. Applied Economics Letters, v. 9, n. 5, p. 331-334, 2002. http://dx.doi. org/10.1080/13504850110067469

LENTZ, R.; MORTENSEN, D. T. Productivity growth and worker reallocation. International Economic Review, v. 43, n. 3, p. 731-749, 2005.

MICHAEL, P.; MATTHEW, T. Performance measurement in facilities management: driving innovation? Property Management, v. 26, n. 4, p. 241-254, 2008. http:// dx.doi.org/10.1108/02637470810894885

MORIKAWA, M. Labor unions and productivity: an empirical analysis using Japanese firm-level data. Labour Economics, v. 17, n. 6, p. 1030-1037, 2010.

NANERE, M. et al. Environmentally adjusted productivity measurement: An Australian case study. Journal of Environmental Management, v. 85, n. 2, p. 350-362, 2007. http://dx.doi.org/10.1016/j. jenvman.2006.10.004

NIN, A. et al. Bridging the gap between partial and total factor productivity measures using directional distance functions. American Journal of Agricultural Economics, v. 85, n. 4, p. 928-942, 2003. http://dx.doi. org/10.1111/1467-8276.00498

OLIVEIRA, J. A. et al. Um estudo sobre a utilização de sistemas, programas e ferramentas da qualidade em empresas do interior de São Paulo. Produção, v. 21, n. 4, p. 708-723, 2011. http://dx.doi.org/10.1590/ S0103-65132011005000044

OLIVEIRA, J. H. R. Método para avaliação de indicadores de sustentabilidade organizacional. 2002. Tese (Doutorado em Engenharia de Produção)-Universidade Federal de Santa Catarina, Florianópolis, 2002. 
OLIVEIRA, U. R.; MARINS, F. A. S.; ALMEIDA, D. A. Integrando técnicas e procedimentos de gestão de operações: uma aplicação em um banco comercial brasileiro de grande porte. Produção, v. 20, n. 2, p. 237-250, 2010. http:// dx.doi.org/10.1590/S0103-65132010005000008

O'MAHONY, M.; TIMMER, M. P. Output, Input and productivity measures at the industry level: the EU KLEMS database. The Economic Journal, v. 119, n. 538, p. 374-403, 2009. http://dx.doi.org/10.1111/j.1468-0297.2009.02280.x

ORGANISATION FOR ECONOMIC CO-OPERATION AND DEVELOPMENT - OECD. Measuring productivity: measurement of aggregate and industry-level productivity growth - OECD manual. Paris: OECD, 2001. 156 p.

ORGANISATION FOR ECONOMIC CO-OPERATION AND DEVELOPMENT - OECD. Revision of international recommendations for index of industrial production. Viena: OECD, 2005a. 33 p. Background paper.

ORGANISATION FOR ECONOMIC CO-OPERATION AND DEVELOPMENT - OECD. Measuring material flows and resource productivity OECD approach and work plan. Nova lorque: OECD, 2005b. 7 p. Preliminary meeting of the UN Committee on Environmental-Economic Accounting information note.

PLATTS, K. A process approach to researching manufacturing strategy. International Journal of Operations \& Production Management, v. 13, n. 8, p. 4-17, 1993. http://dx.doi.org/10.1108/01443579310039533

PLATTS, K. Characteristics of methodologies for manufacturing strategy formulation. Computer Integrated Manufacturing Systems, v. 7, n. 2, p. 93-99, 1994. http:// dx.doi.org/10.1016/0951-5240(94)90003-5

PLATTS, K.; GREGORY, M. Manufacturing audit in the process of strategy formulation. International Journal of Operations \& Production Management, v. 10, n. 9, p. 5-26, 1990. http://dx.doi.org/10.1108/ EUM0000000001264

PLATTS, K. W. et al. Evaluating manufacturing strategy formulation processes. International Journal of Production Economics, v. 46-47, n. 1, p. 233-240, 1996. http://dx.doi.org/10.1016/0925-5273(95)00029-1

PLATTS, K. W. et al. Testing manufacturing strategy formulation processes. International Journal of Production Economics, v. 56-57, n. 1, p. 517-523, 1998. http://dx.doi.org/10.1016/S0925-5273(97)00134-5
SADIKOGLU, E. Integration of work measurement and total quality management. Total Quality Management, v. 16, n. 5, p. 597-605, 2005. http://dx.doi. org/10.1080/14783360500077518

SAHAY, B. S. Multi-factor productivity measurement model for service organization. International Journal of Productivity and Performance Management, v. 54, n. 1, p. 7-22, 2005. http://dx.doi.org/10.1108/17410400510571419

SARKIS, J. Quantitative models for performance measurement systems - alternate considerations. International Journal of Production Economics, v. 86, n. 1, p. 81-90, 2003. http://dx.doi.org/10.1016/S0925-5273(03)00055-0

SENGUPTA, J. K. The measurement of dynamic productivity efficiency. Bulletin ofEconomic Research, v. 51, n. 2, p. 111124, 1999. http://dx.doi.org/10.1111/1467-8586.00074

SHIMIZU, M.; WAINAl K.; AVEDILLO-CRUZ, E. Value added productivity measurement and its practical applications with linkage between productivity and profitability. Tokyo: Japan Productivity Center for Socio-Economic Development, 1997. 223 p.

SINGH, H.; MOTWANI, J.; KUMAR, A. A review and analysis of the state-of-the-art research on productivity measurement. Industrial Management and Data Systems, v. 100, n. 5, p. 234-241, 2000. http://dx.doi. org/10.1108/02635570010335271

SOUSA, R.; VOSS, C. A. Contingency research in operations management practices. Journal of Operations Management, v. 26, n. 6, p. 697-713, 2008. http:// dx.doi.org/10.1016/j.jom.2008.06.001

SPITHOVEN, A. H. G. M. The productivity paradox and the business cycle. International Journal of Social Economics, v. 30, n. 6, p. 679-699, 2003. http://dx.doi. org/10.1108/03068290310474094

SUIT0, K. Total productivity management. Work Studies, v. 47, n. 4, p. 117-127, 1998. http://dx.doi. org/10.1108/00438029810222469

THIOLLENT, M. Metodologia da pesquisa-ação. 6. ed. São Paulo: Cortez, 1994.

UKKO, J.; TENHUNEN, J.; RANTANEN, H. Performance measurement impacts on management and leadership: Perspectives of management and employees. International Journal of Production Economics, v. 110, n. 1-2, p. 3951, 2007. http://dx.doi.org/10.1016/j.ijpe.2007.02.008

\title{
Systemic productivity: concepts and aplications
}

\begin{abstract}
The study of themes related to productivity has occupied a special place in the strategic agenda of enterprises since the beginnings of mass production. Several models, processes and techniques have been developed with the purpose of improving the present performance levels of organizations. The concept of productivity has been following an evolution cycle from one-dimension approach to a systemic view; however, the different techniques used for its measurement are designed only for some of its specific dimensions. There is a need for integrating those techniques through a systemic productivity management model, and this is the main objective of this paper. Starting from a set of theoretical guidelines that represents the systemic productivity management model, a process was developed for its measurement using the Cambridge process approach. This process was refined by interviews with experts and illustrated by a case study simulation.
\end{abstract}

Keywords

Systemic productivity. Organizational performance. Business auditing. 